\title{
Factors Influencing Residents' Decision to Participate in Health Screening in Taiwan: A Qualitative Study
}

\author{
Shih-Ying Chien ${ }^{1,2}$, Ming-Chuen Chuang ${ }^{1}$ I-Ping Chen ${ }^{1}$ \\ ${ }^{1}$ Institute of Applied Arts, National Chiao Tung University, Taiwan \\ ${ }^{2}$ Institute of East Asian Studies, University of California, Berkeley, USA \\ Email: shihying4768@berkeley.edu, shihying4768@gmail.com
}

How to cite this paper: Chien, S.-Y., Chuang, M.-C. and Chen, I.-P. (2020) Factors Influencing Residents' Decision to Participate in Health Screening in Taiwan: A Qualitative Study. Health, 12, 499-513. https://doi.org/10.4236/health.2020.125039

Received: April 23, 2020

Accepted: May 26, 2020

Published: May 29, 2020

Copyright $\odot 2020$ by author(s) and Scientific Research Publishing Inc. This work is licensed under the Creative Commons Attribution International License (CC BY 4.0).

http://creativecommons.org/licenses/by/4.0/ (c) (i) Open Access

\begin{abstract}
Introduction: Chronic diseases have affected the health and quality of life of people in a vast number of countries. Critically, chronic diseases have been rapidly increasing worldwide and inflicting a heavy burden on society. As such, health screening has been applied to reduce individuals' risks of developing chronic diseases and to initiate health promotion or disease prevention. However, the participant rate is low, especially for people living in rural areas. The purpose of this study was to identify the factors that influence people's decisions to undergo health screening. Method: Semi-structured interviews were undertaken for 16 people aged between 30 - 60 years, and all interviewees had never attended health screening at our hospital despite being invited. Interviewees were from four districts in Taiwan: Anle District of Keelung City; and Ruifang, Gongliao, and Wanli Districts of New Taipei City. These districts were sampled to represent urban and rural areas, respectively, and people in these rural areas were suspected to have high risk of metabolic diseases, kidney and lung diseases or cancers. Interviews were audio-recorded and transcribed verbatim, and NVivo 11 was used for data management. Result: Six motivating factors or barriers were identified: 1) Health attitudes and beliefs about the benefits of participating in health screening; 2) expectation of health screening from the perspective of participants; 3) cost consideration; 4) impact of social influence on willingness to participate in health screening; 5) the experiences of health screening; and 6) practical motivations or barriers of undergoing health screening. Conclusion: Health attitudes and beliefs about the benefits of having a health screening, personal health expectations, and free health services were identified as the top three important factors that influence a resident's decision to undergo health screening for chronic diseases in Taiwan.
\end{abstract}




\section{Keywords}

Health Screening, Participant Willingness, Qualitative Study, Urban and Rural, Facilitators and Barriers

\section{Introduction}

Chronic diseases are the leading causes of mortality and disability worldwide [1] [2] [3]. As of 2015, chronic diseases contributed to approximately $60 \%$ of the 56.5 million total deaths, which is only expected to increase by a further $10 \%$ $20 \%$ by the end of 2020 [4] [5] [6] [7].

Chronic diseases not only affect the health and quality of life sufferers, but they are also a major driver of increases in healthcare costs [8] [9] [10]. It has been calculated that chronic disease accounts for approximately $75 \%$ of the aggregate healthcare spending in the U.S., which equates to an estimated yearly cost of US\$5300 per person [11] [12] [13].

Previously studies have shown that early screening is considered to be a key and an effective way to reduce morbidity and mortality associated with chronic diseases [14] [15] [16] [17] and could also reduce the economic impact of chronic disease. However, many individuals reveal that they never participate in preventative screening services for chronic diseases, although community-based health screening services have been available since 1996 around the world [18]; thus, the participation rates are low in many countries, and many chronic diseases are not diagnosed before symptoms appear especially in rural areas [18] [19] [20]. Additionally, people living in rural areas of the U.S. are more likely than people living in urban areas to die prematurely from chronic diseases [21] [22] [23]. Furthermore, people in low and middle-income areas are more at risk of dying from one of the three leading causes of deaths: cardiovascular diseases, cancers and diabetes [24] [25] [26] [27].

In this qualitative study, we aimed to identify characteristics and explore factors that influence whether people in Taiwan undergo health screening for chronic diseases.

\section{Methods}

\subsection{Sampling and Recruitment}

A purposive sample of 16 people who refused the community health screening were recruited randomly and interviewed, and the study was conducted from October to November. Semi-structured interviews were conducted with participants living in four districts in northern Taiwan: Anle District of Keelung City; and Ruifang, Gongliao, and Wanli Districts of New Taipei City. These districts were selected to represent urban and rural areas, respectively, and people in these rural areas were suspected to have high risk of metabolic diseases, kidney and lung diseases or cancers. The sociodemographic and clinical characteristics of participants (by district) are shown in Table 1. 
Table 1. Sociodemographic and Clinical characteristics of participants.

\begin{tabular}{cccc}
\hline District & Sociodemographic characteristics & Clinical characteristics & $\mathbf{n}$ \\
\hline Anle & Urban area (general population) & General chronic diseases (Metabolism) & 4 \\
Ruifang & Rural area (miners) & High risk of lung, liver, and kidney diseases & 4 \\
Wanli & $\begin{array}{c}\text { Rural area (fishermen, high level } \\
\text { of alcohol use) }\end{array}$ & High risk of liver disease and metabolic & 4 \\
& syndrome & 4 \\
Gongliao & $\begin{array}{c}\text { Rural area (close to a nuclear power } \\
\text { plant, retired fishermen) }\end{array}$ & $\begin{array}{c}\text { High risk of liver disease, metabolic } \\
\text { syndrome and various cancers }\end{array}$ & 4 \\
\hline
\end{tabular}

The interviewees were chosen according to gender and eligibility based on age for free community health screening in order to reflect a diverse range of participants. The interview guide was based on open-ended questions. All the interviewees were asked to self-complete a questionnaire that included questions on socio-demographic and health behavior. Following that, a series of questions were proposed by researchers that covered a set of six factors comprising the main evidence-based factors influencing behavior change, such as health belief and attitude, expectations, cost consideration, social influence, experiences of health screening, and service design.

It is important to explore the facilitators and barriers that lead to the participation in health screening and, the current study aimed to provide a qualitative exploration of influences on the decision to attend or not attend a health screening.

\subsection{Data Collection}

Face-to-face interviews were conducted from October to November 2019, and all were conducted by one trained researcher. Before the interviews, the interviewees were required to read the Informed Consent Form (ICF) and were encouraged to ask any questions about this study. Once an individual had all their questions answered and agreed to participate in the study, they signed and dated the consent form. The interviewees understood that their participation was voluntary and that they could withdraw from this study at any time.

In this study, the interviewees were asked to describe their health check experiences, particularly the factors that have influenced as well as could influence their decision to participate in health screening. Each interview lasted between 25 and 40 minutes, and all the interviews were audio-recorded and transcribed verbatim.

\subsection{Data Analysis}

The audio-recorded qualitative data were transcribed verbatim, checked, and then analyzed using the NVivo 11 software. Each transcript was coded according to the questions asked, and the categories were subsequently established.

Two codebooks were generated: one for the interviews of urban city residents and another for the interviews of rural residents. All the interview transcripts were read and compared by two members of the research team, and an evaluation 
of any discrepancies was conducted by a third team member. After discussion and careful consideration among the three team members, the interview data were judged to be accurate and complete.

This study had been approved by the Research Ethics Committee for Human Subject Protection of National Chiao Tung University (IRB No.: NCTU-REC-107-072-e).

\section{Results}

\section{Sample Characteristics}

The study was conducted from October to November 2019. Socio-demographic characteristics were collected using a self-reported questionnaire or were recorded face-to-face by the researcher prior to the interview. Socio-demographic characteristics included gender, age, marital status, education level (illiterate, or elementary school education or above), and occupation status.

A total of 16 participants ( 8 women and 8 men) were included in this study, whose ages ranged from $30-60$ years. Most of respondents were married (56.3\%), 12.5\% were widowed, and 31.2\% were single. Most of the participants were educated (87.5\%) and $12.5 \%$ were illiterate. Among them, 56.3\% were working, $31.2 \%$ were homemakers, and $12.5 \%$ were retired. The analysis was based on data from 16 participants, whose characteristics are summarized in Table 2.

Table 2. Characteristics of the interviewees.

\begin{tabular}{clcc}
\hline & Characteristics & N & $\%$ \\
\hline \multirow{2}{*}{ Gender } & Male & 8 & 50 \\
& Female & 8 & 50 \\
& Under 30 & 2 & 12.5 \\
& $31-40$ & 4 & 25 \\
& $41-50$ & 4 & 25 \\
Marital status & S1 - 60 & 2 & 12.5 \\
& Over 60 & 4 & 25 \\
& Married & 5 & 31.2 \\
& Separated or divorced & 9 & 56.3 \\
& Widowed & 0 & 0 \\
Level of education & Illiterate & 2 & 12.5 \\
& Elementary school & 2 & 12.5 \\
& Secondary school & 3 & 19 \\
& University & 2 & 12.5 \\
& Postgraduate & 4 & 25 \\
Occupational status & Homemaker & 5 & 31 \\
& Retired & 5 & 31.2 \\
& Employed & 2 & 56.3 \\
\hline
\end{tabular}


This study identified six factors that influence people's health behaviors: health belief and attitude, expectations, cost consideration, social influence, experiences of health screening, and service design (Figure 1).

Six factors emerged from the data that we identified as facilitators and barriers: 1) beliefs about the benefits of participating in health screening; 2) expectation of health screening from the perspective of participants; 3) cost consideration; 4) impact of social influence on willingness to participate in health screening; 5) experiences of health screening; and 6) practical facilitators and barriers of having health screening. The relationship between themes and influencing factors are examined in Table 3.

Health Belief and Attitude-reasons why people choose to attend or not attend health screening

Chronic diseases currently represent one of the main causes of mortality in the world, and early detection and early treatment of chronic diseases are crucial towards the prevention of disease progression.

Our research has shown that health attitude and beliefs are factors that influence whether people decide whether to take up a health service. Moreover, this study indicates that health beliefs and attitudes have a significant association with health behavior. In general, subjects who underrate risks and have a resistant

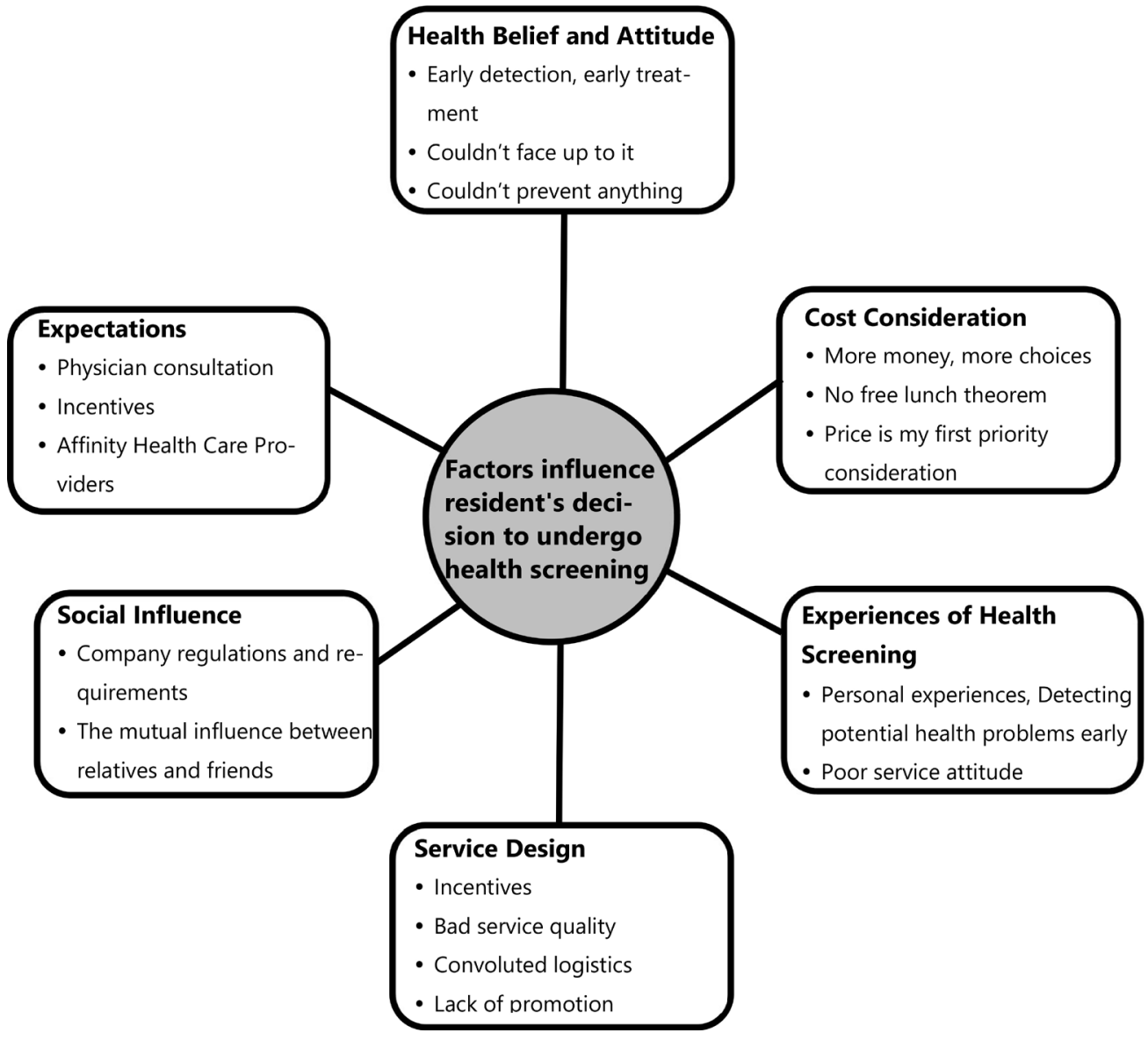

Figure 1. Summary of the factors that influence resident's health screening behavior. 
Table 3. Barriers and facilitators to participation in health screening for chronic diseases.

\begin{tabular}{|c|c|c|}
\hline Themes & Facilitators to uptake & Barriers to uptake \\
\hline $\begin{array}{l}\text { Beliefs about outcome } \\
\text { Reasons why people choose to } \\
\text { attend or not attend health } \\
\text { screening. }\end{array}$ & $\begin{array}{l}\text { Positive Health Belief and Attitude } \\
\text { - Early detection, early treatment } \\
\text { - Nothing is more important than health }\end{array}$ & $\begin{array}{l}\text { Negative Health Belief and Attitude } \\
\text { - The basic examination cannot prevent anything } \\
\text { - I don't think that I would suffer chronic disease } \\
\text { - Worries about already having a dangerous illness or } \\
\text { disease; adopt an "ostrich's policy" }\end{array}$ \\
\hline $\begin{array}{l}\text { Expectations } \\
\text { The needs of health screening. }\end{array}$ & $\begin{array}{l}\text { Expectations (Positive) } \\
\text { - Physician consultation } \\
\text { - Professional treatment and medical expert referral } \\
\text { service provided } \\
\text { - Medical expense deduction } \\
\text { - Incentives }\end{array}$ & $\begin{array}{l}\text { Expectations (Negative) } \\
\text { - Waiting for so long } \\
\text { - Service providers are not friendly } \\
\text { - Useless freebies }\end{array}$ \\
\hline $\begin{array}{l}\text { Social Influence } \\
\text { What/Who can change my } \\
\text { thoughts, feelings, or behavior? }\end{array}$ & $\begin{array}{l}\text { Social Influence (Positive) } \\
\text { - To cooperate with the company regulations and } \\
\text { requirement } \\
\text { - No one can change my mind } \\
\text { - I prefer not to change an established itinerary } \\
\text { because of a health service }\end{array}$ & $\begin{array}{l}\text { Social Influence (Negative) } \\
\text { - The mutual influence between relatives and friends }\end{array}$ \\
\hline $\begin{array}{l}\text { Emotion } \\
\text { After attending health } \\
\text { screening. }\end{array}$ & $\begin{array}{l}\text { Positive experiences of Health Screening } \\
\text { - Have health problems ever been detected by health } \\
\text { screening? }\end{array}$ & $\begin{array}{l}\text { Negative experiences of Health Screening } \\
\text { - Undertaken this on the cheap } \\
\text { - No help } \\
\text { - Unable to coordinate with examination time } \\
\text { - Feels unnecessary as visiting a doctor in Taiwan is } \\
\text { - very affordable and convenient } \\
\text { - Poor service attitude } \\
\text { - No information }\end{array}$ \\
\hline $\begin{array}{l}\text { Practical facilitators and barriers } \\
\text { What happens at health } \\
\text { screening services? }\end{array}$ & $\begin{array}{l}\text { Service Design (Positive) } \\
\text { - Free or low-cost would be beneficial for the poor } \\
\text { - Incentives }\end{array}$ & $\begin{array}{l}\text { - Service Design (Negative) } \\
\text { - Time spent waiting in line } \\
\text { - Hard to follow medical compliance } \\
\text { - Reluctant to change daily routines } \\
\text { - Bad service quality } \\
\text { - Inconvenient transportation } \\
\text { - Lack of physical activity and/or mental energy } \\
\text { - Convoluted logistics } \\
\text { - Cannot match time } \\
\text { - Lack of promotion } \\
\text { - Hard to attend for elderly people, handicapped } \\
\text { people, or shift workers }\end{array}$ \\
\hline
\end{tabular}

attitude towards health promotion seem to be unhealthier compared to other subjects. Therefore, health attitude and beliefs represent important factors that influence whether an individual engages with health screening.

To increase the participation rates of health screening, understanding a person's health attitudes and beliefs is important. These factors not only influence personal health behaviors but also have implications for the promotion of health behaviors. The views of two of the participants are below: 
A relative of mine took a community screening test and found they had colorectal cancer, so I really believe that early detection and early treatment are important:

NO02: Female, urban, age 38

To me, any incentives are secondary. A health checkup should be for your own health. It should be voluntary and have nothing to do with free gifts.

NO03: male, urban, age 48

On the other hand, negative health attitudes and beliefs also affect individual behaviors and habits, which in turn influence health. A common health attitude and belief of having a health screening is that it does not actually prevent disease nor guarantee that one will not get a serious health problem, such as heart disease or diabetes. Some people also "bury their head in the sand" and have the attitude and belief that it is better to not know whether they have a severe illness or disease and not know that they have a high risk of getting a disease in the future. This stems from the notion that people are afraid and cannot confront such truths.

I think community screening tests are very basic, so they can't detect every single health problem and aren't effective in terms of prevention.

NO02: Female, rural, age 38

I know my mom doesn't want to take any screening tests because they are a bother. She doesn't like waiting, and she can't stand for long periods of time. More importantly, she doesn't want to know what diseases she has.

NO01: Female, urban, age 49

Most of my friends and family are unwilling to take screening tests. One moment you' re fine, and the next you have a bunch of diseases. And they are afraid of knowing that they have a disease and don't want to face reality.

NO 13: Female, rural, age 64

\section{Expectations - the needs of health screening}

Health screening is a process of identifying people who may have an increased chance of having or getting a disease or condition. By undergoing health screening, a provider offers information, tests, and treatments to detect potential health disorders or diseases in people who do not have any symptoms of disease. Willingness to participate in health screening is positively associated with personal health expectation; therefore, an understanding of participants' expectations is important. People's expectations, though, of what a healthcare experience encompasses vary widely. In this study, participants held different opinions due to their different socio-demographics and past experiences. Based on this, it is critical to understand the main reasons for participation as well as non-participation and therefore identify strategies to enhance participation in health screening.

\section{Positive expectation}

I think it would be better if community health screening tests also include 
consultations after the tests. I don't really understand all those numbers in the test report, and it would be helpful if a professional could explain what they mean.

NO01: female, urban age 49

If an organization doing the screening could also provide referrals or guidance on treatment plans, it would be really helpful.

NO07: male, rural, age 63

I think incentives would make me more willing to take screening tests. For example, if regular screening tests meant lower clinical and treatment expenses in the future, that would be a great incentive and I would definitely take screening tests.

NO 11: male, urban, age 35

I think having friendly personnel is really important. There are a lot of elderly people around here without their children, so they really desire attention.

NO 02: female, rural, age 38

\section{Negative expectation}

I heard from a friend that there are long waits for every test in community health screening. If there are long waits, $P d$ rather not take the screening tests.

NO 06: female, rural, age 46

In the early years, the medical personnel were not friendly. This has improved, but you still might meet an unfriendly one from time to time.

NO 07: male, rural, age 63

Instead of giving useless free gifts, I think providing better medical services would be better. Reducing the registration fees or medical fees would be better than free gifts.

NO05: male, urban, age 52

\section{Cost Consideration - should health services be free?}

Free medical care has become a hot issue that has attracted some concern from society. Indeed, we found that people have different opinions about whether health services should be free or not, some of which are described below:

Some people believe that there is no such thing as a "free lunch"

I think paid screening tests would be better than free ones. Paid tests are more detailed, and I ve always believed that there's no such thing as a free lunch.

NO05: male, rural, age 52

Paid tests definitely cover more things than free ones, but personally, I don't think the price is the only thing that matters. What matters is whether the test can accurately predict diseases. 
NO 09: female, urban, age 38

I don't think there's a big difference between paid screening tests and free ones. The items they test for are about the same. But it could be that I always take the subsidized ones for public servants, so hospitals are laxer with those.

NO03: male, urban, age 48

On the other hand, some people feel that conducting free health services would encourage individuals to identify their health problems before symptoms appear, and thus the subsequent early treatment would reduce medical expenses in the future.

If they start charging for community health screening tests in the future, $I$ probably won't take them anymore. I d rather find other tests that are free.

NO15: female, rural, age 30

If I feel that there's nothing really wrong with my body, then Pll just take the free screening tests because they' re repetitive.

NO 14: male, rural, age 60

I think most people would be more willing to take these tests if they are free, especially those who are on low incomes or from poorer backgrounds.

NO09: female, urban, age 38

\section{Social Influence - what/who can change my thoughts, feelings, or beha-} vior?

Close personal relationships (e.g., with family and friends) impact individuals' health behaviors, which are especially influential in Asian culture because of the emphasis on the importance of family. Indeed, families and friends are often intimately involved in decisions about changes to health behavior and regularly participate in decisions regarding significant health services (e.g., health screening). These include the types of health checks to consider and whether to undergo them.

I get health checkups mainly because they are a part of company regulations, but I also get them to understand my health and to make sure that there's nothing wrong.

NO 16: male, urban, age 42

I usually go with my husband or coworkers. Once I ve made up my mind, I go through with it even if they back out.

NO09: female, rural, age 38

On the other hand, people sometimes fail to consider the substantial influence of social relationships, which could result in a missed, crucial opportunity for improved health care.

At home, I usually do things with my husband. If I think it suits him, P Il try 
and persuade him. If he still insists on not going, then I probably won't either.

NO 06: female, urban, age 46

\section{Emotion - what happens after attending health screening?}

Our current research has shown that participants' experiences of health screening are the most important factor impacting the effectiveness of continuing participation. An increased willingness to participate is one result of participants receiving help and advice following a health screening, such as arranging preventive treatments. In contrast, once participants have a poor experience with health screening, such as a lack of incentives being subjected to poor service, not only is there a reduced willingness to participate again, but it also creates a negative impression of health screening services overall.

I once got a health checkup at the hospital and found I had a blood sugar control problem, and a relative of mine incidentally found that they had colorectal cancer because of a screening test and got good treatment afterwards. I think it proves that screening can achieve the goal of early discovery and early treatment.

NO9: female, urban, age 38

I never thought that these free tests would be able to prevent anything until I heard that someone discovered something wrong with their body from these tests. That really made me realize what community health screening tests can do.

NO 12: male, rural, age 40

\section{Practical facilitators and barriers - what happens at health screening ser-} vices?

Most respondents said that when deciding whether to participate, the benefits might influence their willingness to participant in health screening. These possible factors were grouped according to facilitators and barriers to attendance.

\section{Facilitators to attend}

Many interviewees responded that incentives may be more influential for participants on lower incomes, such as free or low-cost health service. Furthermore, our research indicates that incentives could result in higher participation rates without any significantly negative impact.

I think most people would be willing to take these tests because they' re free. For the less wealthy, they' re free and you can get a gift. What's not to like? NO 10: female, rural, age 38

If taking regular screening tests meant that I could have reduced medical expenses in the future, that would be a great incentive for me.

NO 12: male, urban, age 40

\section{Barriers to attend}

Previous studies have revealed a wide range of reasons for non-participation 
in health screening. The most common reason for non-participation was that the available times were not suitable for the individual, for example, a lack of time due to work commitments or a reluctance to change time schedules to accommodate health screening. Other reported reasons for non-participation included bad service design, personal reasons, and not motivated to participate.

For me, taking community health screening tests is not easy because they always schedule them during work hours, and I have to work.

NO 12: male, urban, age 40

I usually work rotating shifts, and I wouldn't rearrange my work schedule to get a health checkup. If I had to choose, Id likely forgo the health checkup.

NO04: Female, rural, age 59

Screening tests always have long waiting lines, and the routes are really complicated. First, you' re on the fifth floor, next, you' re on the twelfth, and then you' re on the third. I keep going to the wrong places, so it's such a waste of time.

NO 12: male, urban, age 40

Right now, I think the service quality is poor. It's not easy to get there from the countryside, and the service personnel are ill-mannered. My mother's 82; she does not have the energy nor patience to deal with all that.

NO03: male, rural, age 48

No one around me has ever taken any of these tests before. Because we don't know about them, I think they need to do more to raise awareness. If more people know, then more people will take them.

NO 16: male, rural, age 42

There are more elderly people around here, so they should try to understand what the elderly need. They also need to use the right promotion methods because there are more elderly people in the countryside who can't read.

NO10: female, rural, age 38

\section{Discussion}

\subsection{Summary of the Results}

In this qualitative study, we identified important factors on whether people decide to participate in health screening. These include health beliefs and attitudes, expectations, cost consideration, social influence, experiences of health screening, and service design.

Additionally, facilitators and barriers for people as to whether they participate in health screening for chronic diseases are heterogeneous [28] [29] [30] [31], and these factors play an important role in the decision-making process that leads to the utilization of health services. As a result, service providers should 
take these into serious consideration when planning health services and interventions in the community aimed at the prevention of chronic diseases.

Literature shows that a positive health belief and attitude, positive experiences of health screening, and incentives are facilitators for participation [32] [33] [34] [35], whereas a negative health belief and attitude, a bad impression of a health care service, and negative experiences are barriers [34] [35]. Furthermore, we also identified practical issues that people take into consideration, such as understanding the needs of health screening, providing sufficient incentives [36] [37], and providing medical expertise as well as referral services. This study concludes that for a good and meaningful uptake of health screening, a multifactorial approach is necessary.

\subsection{Strengths and Limitations}

This study has several strengths and limitations. A strength of this study was that it included face-to-face interviews with people who had been invited to participate in health screening, but had never attended. Participants were divided into two parts, urban and rural, and numerical targets were set in each area. This ensured that comparisons of health behavior could be more easily and sufficiently performed between genders as well as among areas of residence. Finally, the findings of the study are supported by existing literature, which gives us confidence in the generalizability of our research.

There are also several limitations of this study. All participants were from the northern parts of Taiwan; therefore, generalizability to all populations is uncertain. In addition, although this study captured a wide range of information about factors influencing a resident's decision to undergo health screening, determining which of these factors plays a more important role in decision-making.

\section{Conclusion}

This qualitative study identified a few critical factors that influence one's decision on whether to attend health screening for chronic diseases. The most common reasons include the following: health belief and attitude, expectations, cost consideration, social influence, experiences, and service design of health screening. Our findings suggest that people are interested in participating if a health service could enhance its efficiency and effectiveness by increasing its focus on a participant's needs. Furthermore, lower participation rates are a global problem and incentives could result in a significant increase in participation rates. Therefore, incentives should be considered when promoting health screening.

\section{Acknowledgements}

We would like to thank all the participants, who shared their opinions and experiences with us. We also thank Dr. Hsu, Chih-Chin, Keelung Chang Gung Memorial Hospital, for his invaluable input during the development stage of the study. This research was supported by the "Academic Exchange and Coopera- 
tion Project" between National Chiao Tung University (Taiwan) and the University of California, Berkeley (U.S.A.).

\section{Founding}

This research was partially supported by a National Chiao Tung University (Taiwan) research fellowship.

\section{Ethics Approval}

Ethical approval to conduct this study was received from the Research Ethics Committee for Human Subject Protection, National Chiao Tung University (REC reference: NCTU-REC-107-072-e). Written informed consent was obtained for each participant.

\section{Conflicts of Interest}

The authors declare no conflicts of interest regarding the publication of this paper.

\section{References}

[1] Lopez, A.D. and Mathers, C.D. (2006) Measuring the Global Burden of Disease and Epidemiological Transitions: 2002-2030. Annals of Tropical Medicine \& Parasitology, 100, 481-499. https://doi.org/10.1179/136485906X97417

[2] Bauer, U.E., Briss, P.A., Goodman, R.A. and Bowman, B.A. (2014) Prevention of Chronic Disease in the 21st Century: Elimination of the Leading Preventable Causes of Premature Death and Disability in the USA. The Lancet, 384, 45-52. https://doi.org/10.1016/S0140-6736(14)60648-6

[3] Kalkonde, Y.V., Deshmukh, M.D., Sahane, V., Puthran, J., Kakarmath, S., Agavane, V., et al. (2015) Stroke Is the Leading Cause of Death in Rural Gadchiroli, India. Stroke, 46, 1764-1768. https://doi.org/10.1161/STROKEAHA.115.008918

[4] Boutayeb, A. and Boutayeb, S. (2005) The Burden of Non-Communicable Diseases in Developing Countries. International Journal for Equity in Health, 4, 2. https://doi.org/10.1186/1475-9276-4-2

[5] Bezek, S., Ujházy, E., Mojmír, M., Navarová, J. and Dubovicky, M. (2008) Developmental Origin of Chronic Diseases: Toxicological Implication. Interdisciplinary Toxicology, 1, 29-31. https://doi.org/10.2478/v10102-010-0029-8

[6] WHO (2003) World Health Report 2002: Reducing Risks, Promoting Healthy Life.

[7] Terzic, A. and Waldman, S. (2011) Chronic Diseases: The Emerging Pandemic. Clinical and Translational Science, 4, 225-226. https://doi.org/10.1111/j.1752-8062.2011.00295.x

[8] Steven, M.P. (2016) Multimorbidity in Chronic Disease: Impact on Health Care Resources and Costs. Risk Management and Healthcare Policy, 9, 143-156. https://doi.org/10.2147/RMHP.S97248

[9] Kang, S.H., Ju, Y.J., Yoon, H.J., Lee, S.A., Kim, W. and Park, E.C. (2018) The Relationship between Catastrophic Health Expenditure and Health-Related Quality of Life. International Journal for Equity in Health, 17, 166.

https://doi.org/10.1186/s12939-018-0883-0 
[10] Daniel, H., Bornstein, S.S. and Kane, G.C. (2018) Addressing Social Determinants to Improve Patient Care and Promote Health Equity: An American College of Physicians Position Paper. Annals of Internal Medicine, 168, 577. https://doi.org/10.7326/M17-2441

[11] Jensen, M.P., Brunklaus, A., Dorris, L., Zuberi, S.M., Knupp, K.G., Galer, B.S., et al. (2017) The Humanistic and Economic Burden of Dravet Syndrome on Caregivers and Families: Implications for Future Research. Epilepsy \& Behavior, 70, 104-109. https://doi.org/10.1016/j.yebeh.2017.02.003

[12] Raghupathi, W. and Raghupathi, V. (2018) An Empirical Study of Chronic Diseases in the United States: A Visual Analytics Approach to Public Health. International Journal of Environmental Research and Public Health, 15, 431. https://doi.org/10.3390/ijerph15030431

[13] Centers for Disease Control and Prevention (2009) The Power of Prevention: Chronic Disease ... the Public Health Challenge of the 21st Century.

[14] Gates, T.J. (2001) Screening for Cancer: Evaluating the Evidence. American Family Physician, 63, 513-522.

[15] Curry, S.J., Byers, T. and Hewitt, M. (2003) Fulfilling the Potential of Cancer Prevention and Early Detection. Oncology Nursing Forum, 31, 648-648.

[16] Lamontagne-Godwin, F., Burgess, C., Clement, S., Gasston-Hales, M. and Barley, E. (2018) Interventions to Increase Access to or Uptake of Physical Health Screening in People with Severe Mental Illness: A Realist Review. BMJ Open, 8, e019412. https://doi.org/10.1136/bmjopen-2017-019412

[17] Norris, S.L., Messina, P.J., Caspersen, C.J., Engelgau, M.M., Jack, L., et al. (2001) Strategies for Reducing Morbidity and Mortality from Diabetes through Health-Care System Interventions and Diabetes Self-Management Education in Community Settings: A Report on Recommendations of the Task Force on Community Preventive Services. Morbidity and Mortality Weekly Report. Recommendations and Reports, 50, 1-15.

[18] Chien, S.-Y., Chuang, M.-C., Chen, I.-P. and Yu, P.H. (2019) Primary Drivers of Willingness to Continue to Participate in Community-Based Health Screening for Chronic Diseases. International Journal of Environmental Research and Public Health, 16, 1645. https://doi.org/10.3390/ijerph16091645

[19] Bobridge, A., Bampton, P., Cole, S., Lewis, H. and Young, G. (2014) The Psychological Impact of Participating in Colorectal Cancer Screening by Faecal Immuno-Chemical Testing-The Australian Experience. British Journal of Cancer, 111, 970-975. https://doi.org/10.1038/bjc.2014.371

[20] Sieverding, M., Decker, S. and Zimmermann, F. (2010) Information about Low Participation in Cancer Screening Demotivates Other People. Psychological Science, 21, 941-943. https://doi.org/10.1177/0956797610373936

[21] Stanhope, M. and Lancaster, J. (2015) Public Health Nursing: Population-Centered Health Care in the Community. 7th Edition, Mosby Elsevier, St. Louis.

[22] Cheng, L., Tan, L., Zhang, L., Wei, S., Liu, L., Long, L., et al. (2013) Chronic Disease Mortality in Rural and Urban Residents in Hubei Province, China, 2008-2010. BMC Public Health, 13, Article No. 713. https://doi.org/10.1186/1471-2458-13-713

[23] Patel, S., Ram, F., Patel, S.K. and Kumar, K. (2019) Association of Behavioral Risk Factors with Self-Reported and Symptom or Measured Chronic Diseases among Adult Population (18-69 Years) in India: Evidence from Sage Study. BMC Public Health, 19, Article No. 560. https://doi.org/10.1186/s12889-019-6953-4

[24] Miranda, J.J., Kinra, S., Casas, J.P., Smith, G.D. and Ebrahim, S. (2008) Noncommunica- 
ble Diseases in Low- and Middle-Income Countries: Context, Determinants and Health Policy. Tropical Medicine and International Health, 13, 1225-1234. https://doi.org/10.1111/j.1365-3156.2008.02116.x

[25] Abegunde, D.O., Mathers, C.D., Adam, T., Ortegon, M. and Strong, K. (2008) The Burden and Costs of Chronic Diseases in Low-Income and Middle-Income Countries. The Lancet, 370, 1929-1938. https://doi.org/10.1016/S0140-6736(07)61696-1

[26] Beaglehole, R., Eppingjordan, J., Patel, V., Chopra, M., Ebrahim, S., Kidd, M., et al. (2008) Improving the Prevention and Management of Chronic Disease in Low-Income and Middle-Income Countries: A Priority for Primary Health Care. The Lancet, 372, 940-949. https://doi.org/10.1016/S0140-6736(08)61404-X

[27] Miranda, J.J., Barrientos-Gutiérrez, T., Corvalan, C., Hyder, A.A., Lazo-Porras, M., Oni, T. and Wells, J.C.K. (2019) Understanding the Rise of Cardiometabolic Diseases in Low- and Middle-Income Countries. Nature Medicine, 25, 1667-1679. https://doi.org/10.1038/s41591-019-0644-7

[28] De, W.A.M., Wändell, P.E., Holzmann, M.J., Korevaar, J.C., Monika, H., Carl, G., et al. (2018) Barriers and Facilitators to Participation in a Health Check for Cardiometabolic Diseases in Primary Care: A Systematic Review. European Journal of Preventive Cardiology, 25, 1326-1340.

[29] Rachlis, B., Naanyu, V., Wachira, J., Genberg, B. and Braitstein, P. (2016) Identifying Common Barriers and Facilitators to Linkage and Retention in Chronic Disease Care in Western Kenya. BMC Public Health, 16, Article No. 741. https://doi.org/10.1186/s12889-016-3462-6

[30] Francis, L., Dunt, D. and Cadilhac, D.A. (2016) How Is the Sustainability of Chronic Disease Health Programmes Empirically Measured in Hospital and Related Healthcare Services?-A Scoping Review. BMJ Open, 6, e010944. https://doi.org/10.1136/bmjopen-2015-010944

[31] Kadu, M.K. and Stolee, P. (2015) Facilitators and Barriers of Implementing the Chronic Care Model in Primary Care: A Systematic Review. BMC Family Practice, 16, 12. https://doi.org/10.1186/s12875-014-0219-0

[32] S., M. and van and den Kloosterboer, K. (2014) An Exploration of Beliefs and Attitudes Regarding Healthy Lifestyle Behaviour in an Urban Population in the Netherlands: Results from a Focus Group Study in a Community-Based Prevention Project. European Journal of Public Health, 25, 467-471. https://doi.org/10.1093/eurpub/cku140

[33] Mäntyselkä, P., Kautiainen, H. and Miettola, J. (2019) Beliefs and Attitudes towards Lifestyle Change and Risks in Primary Care: A Community-Based Study. BMC Public Health, 19, Article No. 1049. https://doi.org/10.1186/s12889-019-7377-x

[34] Dickinson, J.A., Pimlott, N., Grad, R., Singh, H., Szafran, O., Wilson, B.J., Groulx, S., Thériault, G. and Bell, N.R. (2018) Screening: When Things Go Wrong. Canadian Family Physician, 64, 502-508.

[35] Baileff, A. (2000) Cervical Screening: Patients' Negative Attitudes and Experiences. Nursing Standard (Royal College of Nursing (Great Britain): 1987), 14, 35-37. https://doi.org/10.7748/ns2000.07.14.44.35.c2880

[36] Chien, S.Y., Chuang, M.C. and Chen, I.P. (2019) Identifying Service Needs from the Perspective of Service Providers-A Qualitative Study. Health, 11, 489-500. https://doi.org/10.4236/health.2019.115042

[37] Armon, G. and Toker, S. (2013) The Role of Personality in Predicting Repeat Participation in Periodic Health Screening: Personality and Periodic Health Screening. Journal of Personality, 81, 452-464. https://doi.org/10.1111/jopy.12021 